lượng thuốc tê khá cao và tiêm môt lần duy nhất nên dù đã có hướng dẫn của siêu âm nhưng vẫn cần tuyệt đối tuân thủ các nguyên tắc của gây tê vùng để đề phòng biến chứng ngộ độc thuốc tê do tiêm thuốc tê vào mạch máu.

\section{KẾT LUẬN}

Tác dụng không mong muốn của phương pháp gây tê cơ vuông thắt lưng (QL block) hai bên bằng ropivacain $0,25 \%$ (liều $0,3 \mathrm{ml} / \mathrm{kg}$ mỗi bên) tương đương với phương pháp gây tê mặt phẳng cơ ngang bụng (TAP block) hai bên bằng thuốc tê và liều tương tự, dưới hướng dẫn của siêu âm để giảm đau sau mổ cắt tử cung hoàn toàn đường bụng. Không gặp các tai biến nặng nề của cả hai phương pháp này.

\section{TÀI LIÊU THAM KHẢO}

1. Aditianingsih D, Mochtar CA, Chandra S, et al. Comparison of Three-Quadrant Transversus Abdominis Plane Block and Continuous Epidural Block for Postoperative Analgesia After Transperitoneal Laparoscopic Nephrectomy.
Anesth Pain Med. 2018;8(5):e80024. doi:10.5812/ aapm.80024

2. Charlton S, Cyna AM, Middleton P, et al. Perioperative transversus abdominis plane (TAP) blocks for analgesia after abdominal surgery. Cochrane Database Syst Rev. 2010; 12, Cd007705.

3. Chen J, Chen $\mathbf{C}$, Sun $\mathbf{G}$, et al. Quadratus Lumborum Block Versus Transversus Abdominis Plane Block for Postoperative Analgesia in Abdominal Surgery: A Systematic Review and Meta-analysis. BMC Anesthesiol, 2020 Mar 2;20(1):53 https://orcid.org/0000-0002-6001-4530.

4. Chin KJ, McDonnell JG, Carvalho B, et al. Essentials of Our Current Understanding: Abdominal Wall Blocks. Reg Anesth Pain Med. 2017;42(2):133-183. doi:10.1097/AAP.0000000000000545

5. Murouchi $T$, Iwasaki $S$, Yamakage $M$. Quadratus Lumborum Block: Analgesic Effects and Chronological Ropivacaine Concentrations After Laparoscopic Surgery. Reg Anesth Pain Med. 2016;41(2):146-150. doi:10.1097/AAP.0000000000000349.

6. Ueshima $H$, Otake $H$, Lin JA. UltrasoundGuided Quadratus Lumborum Block: An Updated Review of Anatomy and Techniques. Biomed Res Int 2017:2752876. 2017; Epub 2017 Jan 3.

\title{
ĐĂC ĐIỂM HİNH THÁI RĂNG SỐ 8 MỌC LỆCH VÀ BIẾN CHỨNG TỚI RĂNG SỐ 7 HÀM DƯỚI TRÊN PHIM PANORAMA
}

\section{TÓM TẮT}

Vị trí mọc bất thường của răng số 8 gây ra nhiều biến chứng, ảnh hưởng trực tiếp tới sức khỏe của người bênh nhân. Kỹ thuât chup phim răng Panorama đem đến nhiêu lợi ích cho Bác sĩ răng hàm mặt khi khám xét về hình thái răng số 8 , các cấu trúc và những tổn thương lân cận. Nghiên cứu được tiến hành dưa trên kết quả đo đạc của 119 bệnh nhân có chụp phim Panorama. Kết quả của chúng tôi chỉ ra răng số 8 mọc lệch gặp nhiều nhất ở lứa tuổi từ 26-40 tuổi chiếm tỷ lệ $52.94 \%$, mọc lệch gần-góc chiếm tỷ lệ cao nhất $63.26 \%$, mọc nằm ngang $21.95 \%$ và ngâm ngược chiếm tỷ lệ thấp nhất $1.53 \%$. Răng số 8 mọc lệch $>45^{\circ}$ chiếm tỷ lê đa số $62.76 \%$, lệch $46^{\circ}-80^{\circ}$ chiếm tỷ lệ $54.08 \%$.Biển chứng sâu răng chiếm tỷ lể cao nhất $52.88 \%$, sau đó là tốn thương tiêu xương ổ răng chiếm $47.12 \%$, tỷ lệ sâu chưa tổn thương tủy răng 7 chiếm $46.60 \%$, tổn thương đến tủy răng số 7 chiếm $6.28 \%$. Tiêu tổ chức cứng không gặp trong nghiên cứu này. Trong số các biến chứng gặp phải,

*Trường Đại học Kỹ thuật Y tễ Hải Dương Chiu trách nhiệm chính: Nguyễn Hải Niên Email: Nguyenhainien1981@gmail.com Ngày nhận bài: 6.01.2021

Ngày phản biện khoa học: 25.2.2021

Ngày duyệt bài: 8.3.2021

\section{Nguyễn Hải Niên*, Phạm Hữu Thiên*}

biến chứng sâu răng số 7 gặp đa số khi răng số 8 mọc ở tư thế lệch gần-góc chiếm tỷ lệ 69.31\%.

\section{SUMMARY}

THE STUDY OF MORPHOLOGICAL CHARACTERISTICS OF WISDOM TEETH DEVIATE AND COMPLICATIONS AT THE LOWER TTH TEETH IN THE PANORAMA XRAY FILMS

The abnormal erupting position of the No. 8 tooth causes many complications, directly affecting the patient's health. The Panorama dental imaging technique brings many benefits to the orthodontist when examining teeth morphology No. 8, structures and neighboring lesions. The study was conducted based on the measurements of 119 patients with Panorama film. Our results show that the number 8 is most common at the age of $26-40$ years old, accounting for $52.94 \%$, the rate of nearly-angular deviation accounts for the highest rate $63.26 \%$, horizontal growth of $21.95 \%$ and inverted accounting for the lowest rate of $1.53 \%$. Tooth number 8 is deviated $>45^{\circ}$, accounting for the majority of $62.76 \%$, deviation $46^{0}-80^{\circ}$ accounts for $54.08 \%$. Caries complications accounted for the highest rate of $52.88 \%$, followed by alveolar bone resorption, which accounted for $47.12 \%$, the proportion of cavities without damage to tooth marrow 7 accounted for $46.60 \%$, and damage to tooth pulp number 7 
accounted for $6.28 \%$. Rigid digestion was not found in this study. Among the complications encountered, the number 7 tooth decay complications are mostly encountered when the number 8 grows in a nearly angular position, accounting for $69.31 \%$.

\section{I. ĐĂT VẤN ĐỀ}

Răng số 8 là răng mọc cuối cùng của cung răng, nằm ở vị trí xa nhất trên cung hàm, được mọc ở lứa tuổi trưởng thành khi mà các răng khác đã mọc ổn định. Do nhiều nguyên nhân mà răng số 8 thường mọc lệch, gây bất thường về vị trí và kích thước gây ra nhiêu biến chứng, ảnh hưởng tới sức khỏe của bệnh nhân. Trong 4 răng số 8 thì hairăng số 8 hàm dưới là dễ gây biến chứng hơn cả. Những biến chứng có thể kể đến như: viêm quanh thân răng (VQTR), sâu răng, tiêu tổ chức cứng răng số 7 , viêm mô tế bào... Những tai biến đối với răng số 7 thường xảy ra muộn hơn so với các tai biến nhiễm trùng khi mọc rằng[1]. Tổn thương răng số 7 do ảnh hưởng bởi răng số 8 thường bị phát hiện ở giai đoạn muộn khi có những biến chứng. Thế giới và Việt Nam đã có những nghiên cứu liên quan đến vấn đề này như: Nhận xét các biến chứng thường gặp do răng khôn hàm dưới (RKHD) [2]; Nhận xét tình trang mọc răng và kết quả xữ trí các tai biến ở bệnh nhân RKHD bệnh viện răng hàm mặt Trung ương Hà Nội[1]; Nhận xét đặc điểm lẩm sàng, Xquang và đánh giá kết quả phẫu thuật RKHD mọc lệch, mọc ngầm[3]. Tuy nhiên, việc nghiên cứu tiếp là cần thiết do sự đa dạng và phức tạp về hình thái, biến chứng của răng số 8 , nhất là đối với răng số 7 . Để góp phần phòng tránh biến chứng, nâng cao chất lượng chẩn đoán và điều trị, chúng tôi thực hiện đề tài "Đặc điểm hình thái của răng số 8 hàm dưới mọc lệch và biến chứng tới răng số 7 hàm dưới trên phim Panorama" với hai mục tiêu nghiên cứu:

1. Nhận xét hình thái răng số 8 mọc lệch trên phim Panorama.

2. Đánh giá biến chứng của răng số 8 mọc lệch tới răng số7 hàm dưới.

\section{II. ĐỐI TƯỢNG VÀ PHƯƠNG PHÁP NGHIÊN CỨU}

2.1 Đối tượng: Tổng số 119 bệnh nhânđếnkhám răng hàm mặt, có chỉ định chụp phim Panorama từ tháng 01/2019-03/2019 tại Bệnh viện Đại học Kỹ thuật Y tế Hải Dương.

2.2 Phương phápnghiên cứu. Thu thập phim Panorama, xử lý đo đạc bằng phần mềm đọc và vẽ phim chuyên dụng RadiAnt DICOM. Đo và ghi chép phim theo phương pháp Ganss [4]

2.3 Xử lý số liệu. Số liệu được nhập và xử lý bằng phần mềm SPSS 22.0

\section{KẾT QUẢ NGHIÊN CứU}

\section{1. Đặc điểm hình thái răng số 8 mọc lệch.}

Tuổi: Nam chiếm $43.70 \%$. Nữ chiếm $56.30 \%$. Nhóm tuổi từ $26-40$ chiếm $52.94 \%$, nhóm tuổi 18-25 chiếm 42.85\%.

Bảng 3.1.Phân bồ số lượng răng số 8 moc lệch

\begin{tabular}{|c|c|c|c|}
\hline \multicolumn{2}{|c|}{ Đặc điểm } & $\begin{array}{l}\text { Số lượng răng } \\
\text { moc lêch }\end{array}$ & Tổng \\
\hline \multirow{2}{*}{$\begin{array}{l}\text { Hàm } \\
\text { trên }\end{array}$} & R1.8 & 55 & \multirow[b]{2}{*}{107} \\
\hline & R2.8 & 52 & \\
\hline \multirow{2}{*}{$\begin{array}{l}\text { Hàm } \\
\text { dưới }\end{array}$} & R3.8 & 93 & \multirow{2}{*}{196} \\
\hline & R4.8 & 103 & \\
\hline \multicolumn{2}{|c|}{$\begin{array}{l}\text { Răng số } 8 \text { môc } \\
\text { lệch một bên }\end{array}$} & $\mathrm{n}=42$ & $\begin{array}{c}35.29 \\
\%\end{array}$ \\
\hline \multicolumn{2}{|c|}{$\begin{array}{l}\text { Rằng số } 8 \text { mọc } \\
\text { lêch cả hai bền }\end{array}$} & $\mathrm{n}=77$ & $\begin{array}{c}64.71 \\
\%\end{array}$ \\
\hline
\end{tabular}

Nhận xét: Có 77 BN có răng số 8 mọc lệch, ngầm ở cả hai bên hàm dưới chiếm $64.71 \%, B N$ có răng số 8 mọc lệch, ngầm chỉ một bên chiếm $35.29 \%$.

Bảng 3.2. Đặc điểm hình thái cung răng số 8 hàm dưới theo hướng mọc lệch

\begin{tabular}{|c|c|c|c|c|}
\hline \multicolumn{2}{|c|}{$\begin{array}{l}\text { Răng số } 8 \\
\text { Tư thê } \\
\text { răng số } 8\end{array}$} & $\begin{array}{c}\text { Răng } \\
3.8\end{array}$ & $\begin{array}{c}\text { Răng } \\
4.8\end{array}$ & $\begin{array}{l}\text { Tổng } \\
(\%)\end{array}$ \\
\hline $\begin{array}{l}\text { Lệch gần- } \\
\text { góc }\end{array}$ & $\mathrm{n}$ & $\begin{array}{c}51 \\
26.02\end{array}$ & $\begin{array}{c}73 \\
37.24\end{array}$ & $\begin{array}{c}124 \\
63.26\end{array}$ \\
\hline $\begin{array}{l}\text { Lệch xa- } \\
\text { góc }\end{array}$ & $\mathrm{n}$ & $\begin{array}{c}17 \\
8.67\end{array}$ & $\begin{array}{c}9 \\
4.59\end{array}$ & $\begin{array}{c}26 \\
13.26\end{array}$ \\
\hline Nằm ngang & $\mathrm{n}$ & $\begin{array}{c}23 \\
1.73\end{array}$ & $\begin{array}{c}21 \\
10.72\end{array}$ & $\begin{array}{c}44 \\
22.45\end{array}$ \\
\hline $\begin{array}{l}\text { Ngầm } \\
\text { ngược }\end{array}$ & $\mathrm{n}$ & $\begin{array}{c}2 \\
1.03\end{array}$ & $\begin{array}{l}0 \\
0\end{array}$ & $\begin{array}{c}2 \\
1.03\end{array}$ \\
\hline Tổng & & $\begin{array}{c}93 \\
47.44\end{array}$ & $\begin{array}{c}103 \\
52.56\end{array}$ & $\begin{array}{l}196 \\
100\end{array}$ \\
\hline
\end{tabular}

Nhânn xét: Trên 196 răng số 8 mọc lệch: Mọc lệch gẩn-góc chiếm tỷ lệ $63.26 \%$,mọc lệch nằm ngang chiếm tỷ lệ $22.45 \%$, mọc lệch xa-góc $13.26 \%$, mọc ngầm ngược $1.03 \%$.

Bảng 3.3. Bảng phân bố hình thái học răng số 8 theo góc lệch

\begin{tabular}{|c|c|c|c|c|}
\hline \multicolumn{2}{|c|}{$\begin{array}{l}\text { Răng số } 8 \\
\text { Góc lệch }\end{array}$} & $\begin{array}{c}\text { Răng } \\
3.8\end{array}$ & $\begin{array}{c}\text { Răng } \\
4.8\end{array}$ & $\begin{array}{c}\text { Tống } \\
\text { số(\%) }\end{array}$ \\
\hline $10^{0}-45^{0}$ & $\mathrm{n}$ & $\begin{array}{c}33 \\
16,84\end{array}$ & $\begin{array}{c}40 \\
20,40\end{array}$ & $\begin{array}{c}73 \\
37,24\end{array}$ \\
\hline $46^{0}-80^{0}$ & $n$ & $\begin{array}{c}51 \\
26,02\end{array}$ & $\begin{array}{c}55 \\
28,06\end{array}$ & $\begin{array}{c}106 \\
54,08\end{array}$ \\
\hline 8 & $\mathrm{n}$ & $\begin{array}{c}9 \\
4,59\end{array}$ & $\begin{array}{c}8 \\
4,09\end{array}$ & $\begin{array}{c}17 \\
8,68\end{array}$ \\
\hline \multicolumn{2}{|c|}{ Tổng } & $\begin{array}{c}93 \\
47,45\end{array}$ & $\begin{array}{c}103 \\
52,55\end{array}$ & $\begin{array}{l}196 \\
100\end{array}$ \\
\hline
\end{tabular}

Nhận xét: Trong số 196 răng số 8 mọc lệch góctừ $10^{\circ}-45^{\circ}$ và $46^{\circ}-80^{\circ}$ chiếm tỳ lệ lần lượt là 
$37.24 \%$ và $54.08 \%$, tỷ lệ nhóm răng mọc lệch $80^{0}-90^{\circ}$ chiếm $8.68 \%$.

Bảng 3.4. Bảng phân bố hình thái học răng số 8 theo khoảng rộng xương

\begin{tabular}{|c|c|c|}
\hline $\begin{array}{c}\text { Tương quan } \\
\text { khoảng rộng xương }\end{array}$ & Số răng & $\begin{array}{c}\text { Tỷ lệ } \\
(\%)\end{array}$ \\
\hline Loại I & 39 & 1.90 \\
\hline Loại II & 150 & 76.53 \\
\hline Loại III & 7 & 3.57 \\
\hline Tống & $\mathbf{1 9 6}$ & $\mathbf{1 0 0}$ \\
\hline
\end{tabular}

Nhân xét: Khoảng rộng xương loại loại I với $19.90 \%$, II chiếm tỷ lệ $76.53 \%$, loại III chiếm $3.57 \%$.
Bảng 3.5. Bảng phân bố hinh thái học răng số 8 theo độ sâu

\begin{tabular}{|c|c|c|}
\hline $\begin{array}{c}\text { Tương quan theo } \\
\text { độ sâu }\end{array}$ & Số răng & $\begin{array}{c}\text { Tỷ lệ } \\
\text { (\%) }\end{array}$ \\
\hline Vị trí A & 104 & 53.06 \\
\hline Vị trí B & 85 & 43.37 \\
\hline Vị trí C & 7 & 3.57 \\
\hline Tống & $\mathbf{1 9 6}$ & $\mathbf{1 0 0}$ \\
\hline
\end{tabular}

Nhân xét: Răng số 8 mọc lệch ở vị trí $A$ chiếm $53.06 \%$, vị trí B chiếm $43.37 \%$ và ở vị trí $\mathrm{C}$ chiếm $3.57 \%$. Răng số 8 kẹt răng số 7 gây biến chứng tới răng số 7 (78.06\%), không kẹt răng số 7 chiếm $21.94 \%$.

3.2. Đánh giá các tổn thương tới răng số 7 do răng số 8 mọc lêch

Bảng 3.6. Các biến chứng thường gặp tới răng số 7 do răng số 8 mọc lệch

\begin{tabular}{|c|c|c|c|c|}
\hline Biến chứng & R38 & $\mathbf{R 4 8}$ & Tống số & Tỷ lệ \% \\
\hline Sâu răng chưa tốn thương tủy răng số 7 & 47 & 42 & 89 & 46.60 \\
\hline Tốn thương đến tủy răng số 7 & 4 & 8 & 12 & 6.28 \\
\hline Tiêu XOR & 41 & 49 & 90 & 47.12 \\
\hline Tiêu tố chức cứng răng số 7 & 0 & 0 & 0 & 0 \\
\hline Tống & $\mathbf{9 2}$ & $\mathbf{9 9}$ & $\mathbf{1 9 1}$ & $\mathbf{1 0 0}$ \\
\hline
\end{tabular}

Nhân xét: Trong số 196răng số 8 mọc lệch, biến chứng sâu răng 7 chiếm $52.88 \%$. Tiêu xương ổ răng chiếm $47.12 \%$. Sâu chưa tổn thương tủy răng số 7 chiếm $46.60 \%$, tổn thương đến tủy răng số $7(6.28 \%)$.

Bảng 3.7.Tương quan biến chứng thường gặp và tư thế của răng số 8

\begin{tabular}{|c|c|c|c|c|c|}
\hline Tứ thến chứng & $\begin{array}{c}\text { Lệch gần- } \\
\text { góc }\end{array}$ & $\begin{array}{c}\text { Lệch xa- } \\
\text { góc }\end{array}$ & $\begin{array}{c}\text { Năm } \\
\text { ngang }\end{array}$ & $\begin{array}{c}\text { Nămm } \\
\text { ngược }\end{array}$ & $\begin{array}{c}\text { Tống } \\
\text { Tý lệ (\%) }\end{array}$ \\
\hline Sâu răng số 7 & $70(69.31)$ & $4(3.96)$ & $27(26.73)$ & $0(0)$ & $101(100)$ \\
\hline Tiêu xương ố răng & $67(74.44)$ & $3(3.33)$ & $19(21.11)$ & $1(1.12)$ & $90(100)$ \\
\hline
\end{tabular}

Nhận xét: Biến chứng sâu răng số 7 ở tư thế lệch gần-góc $69.31 \%$, tiêu xương ổ răng ở tư thế lệch gẩn-góc $74.44 \%$.

Bảng 3.8. Tương quan biến chứng hay gặp của răng số 7 và răng số8

\begin{tabular}{|c|c|c|c|c|}
\hline Biến chứng Vị trí & Vị trí A & Vị trí B & Vị trí C & $\begin{array}{c}\text { Tống } \\
\text { Tỷ lệ (\%) }\end{array}$ \\
\hline Sâu răng số 7 & $57(56.44)$ & $42(41.58)$ & $2(1.98)$ & $101(100)$ \\
\hline Tiêu xương ố răng & $48(53.33)$ & $40(44.44)$ & $2(2.23)$ & $90(100)$ \\
\hline
\end{tabular}

Nhận xét: Biến chứng sâu răng số 7 : Vị trí $A$ chiếm $56.44 \%$, vị trí B chiếm $41.58 \%$, vị trí $C$ chiếm $1.98 \%$. Biến chứng tiêu xương ổ răng: Vị trí A-B không có sự khác biệt nhiều.Tiêu tổ chức cứng răng số 7 không gặp ở nghiên cứu này.

Bảng 3.9. Nhận xét biến chứng hay gặp của răng số 7 và khoảng rộng xương

\begin{tabular}{|c|c|c|c|c|}
\hline Biến chứng Loại & Loại I & Loại II & Loại III & Tổng \\
\hline Sâuu răng số 7 & $19(18.82)$ & $80(79.21)$ & $2(1.97)$ & $101(100)$ \\
\hline Tiêu XOR & $20(22.22)$ & $68(75.56)$ & $2(2.22)$ & $90(100)$ \\
\hline
\end{tabular}

Nhận xét: Biến chứng sâu răng số 7 chiếm tỷ lệ khoảng rộng xương loại II $79.21 \%$, loại I chiếm $18.82 \%$. Tiêu xương ổ răng chiếm ở khoảng rộng xương loại II $75.56 \%$, loại I xếp thứ hai $22.22 \%$ và cuối cùng là loại III 2.22\%.

IV. BÀN LUẬN

4.1. Đặc điểmchung phân bố mọc lệch răng số 8. Qua nghiên cứu trên 119 bệnh nhân có phim Panorama có răng số 8 mọc lệch gây biến chứng răng số 7 có $43.70 \%$ nam và $56.30 \%$ nữ. Kết quả này tương đồng với một số nghiên cứu trong nước, cho thấy được sự phân bố trên nam và nữ.

\begin{tabular}{|c|c|c|c|c|c|}
\hline Giới Tác giả & $\begin{array}{c}\text { Phạm Công } \\
\text { Minh }\end{array}$ & $\begin{array}{c}\text { Lê Ngọc } \\
\text { Thanh }\end{array}$ & $\begin{array}{r}\text { Bùi Tha } \\
\text { Ngoan }\end{array}$ & $\begin{array}{l}\text { Lê Nho } \\
\text { Chuyên }\end{array}$ & \\
\hline
\end{tabular}




\begin{tabular}{|c|c|c|c|c|c|}
\hline Nam & $51.2 \%$ & $51.8 \%$ & $53.18 \%$ & $48.72 \%$ & $43.70 \%$ \\
\hline Nữ & $48.8 \%$ & $48.2 \%$ & $46.82 \%$ & $51.28 \%$ & $56.30 \%$ \\
\hline
\end{tabular}

Nghiên cứu chúng tôi chỉ ra rằng phần lớn bệnh nhân khi chụp phim Panorama đều thấy hình ảnh cả hai răng số 8 hàm dưới mọc lệch, tỷ lệ này chiếm $64.71 \%$. Như vậy chụp Xquang Panorama có điểm ưu việt hơn so với phương pháp chụp răng cận chóp, khi mà BN chỉ có dấu hiện sưng, đau một bên răng nhưng khi chụp lại phát hiện thêm cả răng số 8 mọc lệch ở cả bên còn lại, cũng như hai răng số 8 hàm trên.

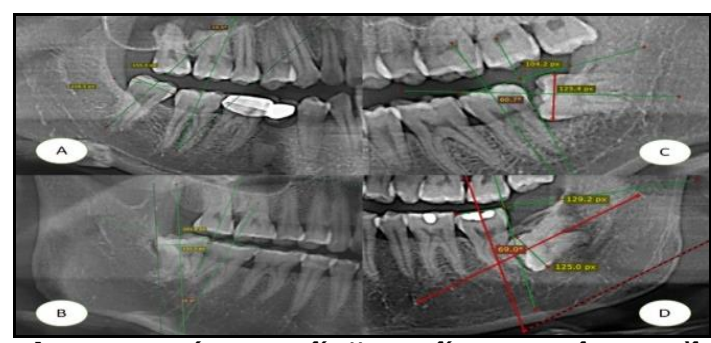

\section{2 Đặc điểm về hình thái học của răng}

Một số nghiên cứu về hình thái răng số 8 mọc lệch được tổng hợp theo bảng sau:

\begin{tabular}{|c|c|c|c|c|c|}
\hline Tư thế & $\begin{array}{c}\text { Phạm Công } \\
\text { Minh }\end{array}$ & $\begin{array}{c}\text { Lê Ngọc } \\
\text { Thanh }\end{array}$ & $\begin{array}{l}\text { Bùi Thi } \\
\text { Ngoan }\end{array}$ & $\begin{array}{l}\text { Lê Nho } \\
\text { Chuyên }\end{array}$ & $\begin{array}{l}\text { Nghiên } \\
\text { cứu }\end{array}$ \\
\hline Gần-góc & \multirow{2}{*}{64.4} & \multirow{2}{*}{68.70} & \multirow{2}{*}{67.40} & 71.79 & 63.26 \\
\hline Năm ngang & & & & 21.79 & 22.45 \\
\hline Xa-góc & 1.7 & 4.8 & 4.48 & 6.42 & 13.26 \\
\hline Ngâmngược & 0 & 0 & 0 & 0 & 1.03 \\
\hline Lệch má & 8.5 & 8.4 & 6.18 & 0 & 0 \\
\hline Lệch lưỡi & 0 & 3.6 & 2.46 & 0 & 0 \\
\hline
\end{tabular}

Kết qủa nghiên cứu của chúng tôi cho thây được răng số 8 mọc ở các tư thế khác nhau, răng số 8 mọc lệch gần-góc là tư thế hay gặp nhất $63.26 \%$. Kểt quả này tương tự nhưPhạm Công Minh, Lê Ngọc Thanh, Bùi Thị Ngoan. Nghiên cứu của chúng tôi cũng chỉ ra rằng góc lệch răng số 8 khá tương đồng với một số nghiên cứu. Nghiên cứu cho thấy độ lệch $>45^{\circ}$ chiếm $62.76 \%$, kết quả này tương tự với nghiên cứu của các tác giả khác. Trong đó tỳ lệ lệch gần

Hình 4.1. Các tư thế răng số 8 mọc lệch, ngầm A. Mọc gần- góc; B. Mọ xa- góc; C. Nằm ngang; D. Ngầm ngược

từ $46^{\circ}-80^{\circ}$ chiếm $54.8 \%$.

4.3 Đặc điểm vị trí độ sâu của răng số 8 với răng số 7 . Dựa vào tương quan điểm cao nhất của răng số 8 so với mặt nhai răng số 7 chúng tôi thây răng số 8 mọc ở vị trí $A$ chiếm $53.06 \%$, vị trí $B$ chiếm $43.37 \%$ và ở vị trí $C$ chiếm $3.57 \%$. Kết quả của nghiên cứu thu được tương đồng với kết quả của Lê Nho Chuyên, Phạm Công Minh và Bùi Thanh Ngoan.

\begin{tabular}{|c|c|c|c|c|c|}
\hline Vị trí Tác Giả & $\begin{array}{c}\text { Bùi Thanh } \\
\text { Ngoan }\end{array}$ & $\begin{array}{c}\text { Phạm Như } \\
\text { Hải }\end{array}$ & $\begin{array}{c}\text { Phạm Công } \\
\text { Minh }\end{array}$ & $\begin{array}{c}\text { Lê Nho } \\
\text { Chuyên }\end{array}$ & $\begin{array}{c}\text { Nghiên } \\
\text { cứu }\end{array}$ \\
\hline A1 & 49.38 & 34 & 20.3 & 14.1 & \multirow{2}{*}{53.06} \\
\cline { 1 - 3 } A2 & 44.45 & 59 & 52.5 & 44.87 & 43.37 \\
\hline B & 6.17 & 7 & 25.4 & 41.03 & 4.1 \\
\hline C & 34 & 2.1 & 0 & 3.57 \\
\hline
\end{tabular}

Qua nghiên cứu trên 119 trường hợp thấy rằng khoảng rộng xương hàm dưới loại II chiếm $76.53 \%$. Kết quả này có tỷ lệ cao hơn nghiên cứu của tác giả Phạm Minh Công, Bùi Thanh Ngoan. Kết quả này có thể cho thấy răng số 8 mọc lệch, ngầm phụ thuộc rất nhiều vào sự phát triển của cung răng hàm dưới và phải có khoảng rộng xương đủ rộng để răng số 8 có thể mọc thẳng. Điều này được chứng minh bằng tỷ lệ khoảng rộng xương loại I chiếm đến $19.90 \%$ ở nghiên cứu của tôi thấp hơn các nghiên cứu khác. Khoảng rộng xương cũng là một yếu tố quxết định đến mức độ khó hay dễ khi thực hiện phâuu thuật nhổ răng số 8 , quyết định đường đi

khi thực hiện lấy răng số 8 ra khỏi cung răng hàm.

\begin{tabular}{|c|c|c|c|}
\hline $\begin{array}{r}\text { Khoáng rộng } \\
\text { Kương }\end{array}$ & $\begin{array}{c}\text { Phâm } \\
\text { Công } \\
\text { Minh }\end{array}$ & $\begin{array}{c}\text { Bùi } \\
\text { Thanh } \\
\text { Ngoan }\end{array}$ & $\begin{array}{c}\text { Nghiên } \\
\text { cứu }\end{array}$ \\
\hline I & 32.2 & 48.15 & 19.90 \\
\hline II & 67.8 & 50.62 & 76.53 \\
\hline III & 0 & 1.23 & 3.57 \\
\hline
\end{tabular}

4.4 Mức độ tốn thương răng số 7 do răng số 8 mọc lệch. Kết quả nghiên cứu của chúng tôi chỉ ra các biến chứng thường gặp là: tiêu xương ổ răng, sâu răng. Trong đó tỷ lệ sâu răng chiếm $52.88 \%$, tiêu xương ổ răng $47.12 \%$. Đây cũng là một tỷ lệ khá cao cho thấy rằng khá nhiều bệnh nhẩn đến khám với các cơn đau tủy 
cấp tính hoăc biến chứng của bênh lý tủy.Vì vây, việc phát hiện và xử lý các trường hợp răng số 8 mọc lệch kịp thời là việc hết sức quan trọng đối với sức khỏe răng miệng và tính thẩm mỹ.

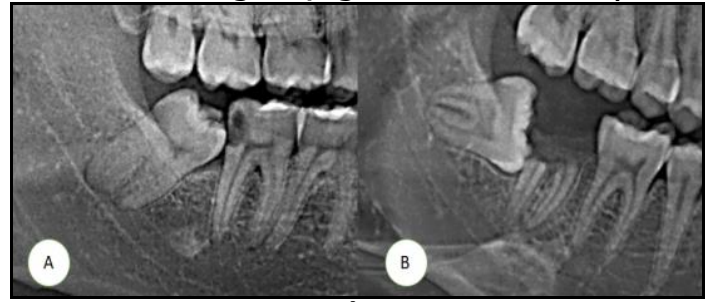

Hình 4.2. Hình ảnh tổn thương sâu răng số 7 (A. Sâu chưa tổn thương tủy; $B$. Sâu răng gây tôn thương tủy)

4.5 Mối liên quan những biến chứng hay găp của răng số 7 với hình thái mọc răng số 8, khoảng rộng xương. Dựa trên kết quả thu được [Bảng 3.7]chúng tôi nhận thây rằng trong các biến chứng mà răng số 7 gặp phải do răng số 8 mọc lệch gây ra thì răng số 8 mọc lệch, ngầm ở tư thế lệch gần-góc gây ra biến chứng chiếm tỷ lệ là cao nhất cũng như gặp nhiều biến chứng cùng lúc nhất (sâu răng- tiểu xương ổ răng). Kết quả trên có được là do tư thế răng số 8 mọc lệch gần- góc khiến cho mặt nhai răng 8 có thể tiếp xúc với tổ chức răng số 7 phần mă̆t xa, gây hiện tượng thức ăn thừa ket lại ở khoảng trống giữa hai răng trong một khoảng thời gian sẽ gây ra hiện tượng sâu răng số 7 thậm chí có cả răng số 8 . Khoảng rông xương loai II gây ra biến chứng tới răng số 7 nhiều nhất. Trong đó, sâu răng số 7 chiếm $79.21 \%$, tiêu xương ổ răng chiếm $75.56 \%$. Khoảng rộng xương loại II gây ra biến chứng cao nhất tới răng số 7 cho thấy xu hướng kém phát triển của xương hàm dưới dẫn đến răng số 8 không có đủ chố để mọc thẳng dẫn đến các biến chứng. Răng số 8 vẫn mọc lệch ở khoảng rộng xương I nhưng mặc dù răng số 8 mọc lệch nhưng vẫn có đủ chỗ khiến răng số 8 chưa gây các ảnh hưởng trực tiếp giống như khoảng rộng xương II. Lý do bởi sự phát triển của cuộc sống khiến cho con người hiện nay đã ăn uống thức ăn mềm hơn, chức năng của các răng hàm để cắn, xé thức ăn không còn được sử dụng nhiều và cần thiết như trước dẫn đến sư thích nghi của xương hàm dưới nhỏ dân, từ đó dẫn đến sự moc lệch, ngầm của răng số 8 do không đủ chỗ, khiến mặt nhai răng số 8 tiếp xúc với mặt xa răng số 7 gây ra sâu răng.

\section{KẾT LUÂ̂N}

- Răng số 8 mọc lệch gặp nhiều nhất ở lứa tuổi từ 26-40 tuổi chiếm 52.94\%, mọc lệch gần- góc chiếm $63.26 \%$, tiếp theo đến mọc nằm ngang $21.95 \%$ và ngầm ngược chiếm tỷ lệ thấp nhất $1.53 \%$.Răng số 8 mọc lệch $>45^{\circ}$ chiếm $62.76 \%$ trong đó góc lêch $46^{\circ}-80$ chiếm tỷ lê $54.08 \%$.Tương quan khoảng rộng xương loai II chiếm $76.53 \%$, khoảng rộng xương loại I chiếm $19.90 \%$.Tương quan theo độ sâu ở vị trí A chiếm $53.06 \%$, độ sâu ở vị trí B chiếm 43.37\%.Tương quan răng số 8 mọc ket chiếm tỷ lệ $78.06 \%$ so với tỷ lệ không kẹt là $21.94 \%$.

- Hai biến chứng răng số 7 hay gặp đó là sâu răng vàtiêu xương ổ răng. Biến chứng sâu răng chiếm $52.88 \%$, tổn thương tiêu tiêu xương ổ răng chiếm $47.12 \%$, tỷ lệ sâu răng chưa tổn thương tủy răng 7 chiếm $46.60 \%$, tổn thương đến tủy răng số 7 (6.28\%). Trong số các biến chứng gặp phải, biến chứng sâu răng số 7 gặp đa số khi răng số 8 mọc ở tư thế lệch gần-góc chiếm tỷ lệ $69.31 \%$; tương quan khoảng rộng xương loại II chiếm tỷ lệ $79.21 \%$; tương quan với vị trí A1, A2 chiếm tỷ lê $56.44 \%$.Biến chứng tiêu xương ổ răng gặp đa số khi răng số 8 mọc ở tư thế lệch gần-góc chiếm tỷ lệ 74.44\%; tương quan khoảng rộng xương loai II chiếm tỷ lê $75.56 \%$; tương quan với vị trí $A 1, A 2$ chiếm tỷ lệ $53.33 \%$.

\section{TÀI LIÊU THAM KHẢO}

1. Nguyễn Tiến Vinh (2010). "Nhận xét tình trang mọc răng và kết quả xử trí các tai biến ở bệnh nhân RKHD bệnh viện răng hàm mặt Trung ưởng Hà Nội". Trướng Đai hoc Y Hà Nôi, Hà Nôii.

2. Phạm Công Minh (2014). "Nhận xét các biến chứng thường gặp do RKHD". Trường Đai học $Y$ Hà Nội, Hà Nội.

3. Lê Ngoc Thanh (2005). "Nhânn xét đặc đ̛̣î̉m lâm sàng, Xquang và đánh giá kết quả phẫu thuât RKHD mọc lệch, mọc ngâm". Trường đại học Y Hà Nội, Hà Nội.

4. McArdle LW, McDonald F, Jones J (2014). "Distal cervical caries in the mandibular second molar: an indication for the prophylactic removal of third molar teeth? Update". British Journal of Oral and Maxillofacial Surgery 52. pp 185-189

5. Lê Nho Chuyên (2016). "Đặc điểm hình thái của răng khôn hàm dưới mọc ị̣̂̂ch, ngầm và biến chứng tới răng hàm lớn thứ hai hàm dưới trên phim panorama tại khoa răng hàm mă̆t bệnh viện GTVT 2015-2016". 'Trường Đai họ Y Hà Nôi, Hà Nội.

6. Bùi Thanh Ngoan (201i). "Nhận xét về mối quan hệ giữa hình thái học và các biến chứng của RKHD". Trường Đại học Y Hà Nội, Hà Nội.

7. Chu FC, Li TK, Lui VK at el (2003), "Prevalence of impacted teeth and associated pathologies-a radiographic study of the Hong Kong Chinese population". Hong Kong Med J. Jun;9(3):158-63.

8. Afzal $M$, Sharrif $M$, Junaid $M$, at el (2013). "Prevelance of radiographic classification of impacted mandibular third molars". Pakistan oral \& Dental journal. Vol 33, No 3.0 